\title{
PROSÓDIA NA LIBRAS - UM ESTUDO DO CORPUS DO ENEM-2017
}

\author{
PROSODIA EM LA LENGUA BRASILEÑA DE SEÑAS - UM ESTUDIO DEL CORPUS \\ DEL ENEM-2017
}

PROSODY IN BRAZILIAN SIGN LANGUAGE - A CORPUS STUDY OF ENEM-2017

\author{
Rúbia Carla da SILVA ${ }^{1}$ \\ Ana Paula de Oliveira SANTANA ${ }^{2}$
}

\begin{abstract}
RESUMO: As articulações faciais refletem subcomponentes prosódicos das línguas orais e sinalizadas. Trata-se de uma pesquisa de natureza aplicada, documental, de caráter descritivoexploratório, através do método observacional. Objetiva-se compreender quais movimentos faciais de manifestação prosódica de entonação na Libras e suas significações em contexto narrativo. Como procedimento metodológico, optou-se por uma revisão bibliográfica sobre a American Sign Language (ASL) e a Língua de Sinais israelense, e pela análise de uma questão da prova do Exame Nacional do Ensino Médio (ENEM) de 2017 - primeira edição em Libras. Como resultados, foram criadas tabelas sobre os movimentos dos elementos faciais superiores e suas significações, verificando-se a relevante contribuição da pesquisa para a legitimação linguística da Libras, para estudos sobre ensino e aprendizagem das línguas de sinais para a significação, compreensão e produção da linguagem. Evidencia-se, portanto, a necessidade de novos olhares e pesquisas acerca da linguística da Libras, devido à escassez de estudos publicados.
\end{abstract}

PALAVRAS-CHAVE: Prosódia. Entonação. Língua de sinais.

RESUMEN: Las articulaciones faciales reflejan subcomponentes prosódicos del lenguaje oral y de señas. Se trata de una investigación de naturaleza aplicada, documental, de carácter descriptivo-exploratorio, a través del método observacional. Se objetiva comprender cuales son los movimientos faciales de manifestación prosódica de entonación en Lengua Brasileña de Señas y sus significaciones en el contexto narrativo. Como procedimiento metodológico, se optó por una revisión bibliográfica sobre la Lengua Americana de Señas y la Lengua de Señas Israelí, y por el análisis de una pregunta del test del Examen Nacional de la Enseñanza Media (ENEM) de 2017 - primera edición en Lengua Brasileña de Señas. Como resultados, fueron creadas tablas a cerca de los movimientos de los elementos faciales superiores y sus significaciones, verificándose la relevante contribución de la pesquisa para la legitimación lingüística de la Lengua Brasileña de Señas, para estudios sobre la enseñanza y el aprendizaje de las lenguas de señas, para la significación, comprensión y producción del lenguaje. Es evidente, por lo tanto, la necesidad de nuevas miradas e investigaciones acerca de la lingüistica de la Lengua Brasileña de Señas, debido a la escasez de estudios publicados.

PALABRAS CLAVE: Prosodia. Entonación. Lengua de señas.

\footnotetext{
${ }^{1}$ Universidade Federal de Santa Catarina (UFSC), Florianópolis - SC - Brasil. Doutoranda no Programa de PósGraduação em Linguística. ORCID: https://orcid.org/0000-0003-0285-909X. E-mail: silvablum@gmail.com ${ }^{2}$ Universidade Federal de Santa Catarina (UFSC), Florianópolis - SC - Brasil. Professora Associada no Curso de Fonoaudiologia e no Programa de Pós-Graduação em Linguística. Doutorado em Linguística (UNICAMP). ORCID: https://orcid.org/0000-0002-9508-9866. E-mail: anaposantana@hotmail.com
} 
ABSTRACT: Facial joints reflect on prosodic subcomponents of oral and sign languages. Therefore, it is a research of an applied, documentary, of a descriptive-exploratory character, through the observational method. The objective is to understand which are the facial movements of intonational prosodic manifestation in Brazilian Sign Language and what it means in a narrative context. As a methodological procedure, we opted for a bibliographic review about American Sign Language (ASL) and Sign Language Israeli and the analysis of a question of the High School National Exam (ENEM) of 2017 - the first edition of the test in Brazilian Sign Language. As results, were created a table about elements of superior facial movements and their means, furthermore verify a relevant contribution to research for the linguistic legitimization of Brazilian Sign Language, for the analyses about teaching and learning sing languages, for the signification, comprehension, and production parlance. Consequently, emphasize a new look and research about the linguistic of Brazilian Sign Languages, due to the scarceness of this publication studies.

KEYWORDS: Prosody. Intonation. Sign Language.

\section{Introdução}

Apesar da intensificação de pesquisas no Brasil direcionadas à Língua Brasileira de Sinais (Libras), permanecem lacunas importantes no que compete aos aspetos relacionados à modalidade, à estrutura linguística, à estilística e aos aspectos literários. A grande maioria das publicações está direcionada aos aspectos educacionais bilíngues e/ou inclusivos dos sujeitos surdos na educação básica, ao letramento dos surdos, e outra parcela direcionada aos estudos da tradução e interpretação bimodal. Contudo, nas últimas décadas tem-se observado um importante interesse de diferentes áreas em torno da Língua Brasileira de Sinais. O campo da linguística tem contribuído com a caracterização da natureza da língua de sinais, relacionados à aquisição e processamento da linguagem (DUARTE; MESQUITA, 2016).

No campo educacional, essas discussões reverberam de forma significativa para e em cada um dos atores envolvidos na perspectiva bilíngue, como na educação inclusiva. Professores surdos, intérpretes, professores bilíngues, profissionais do Atendimento Educacional Especializado (AEE), entre outros agentes da educação, precisam compreender com maior aprofundamento as questões relacionadas à Libras, para entenderem e considerarem que a entonação da língua de sinais contribui diretamente para sua significação. Dessa maneira, o que já está garantido na legislação, como a Lei 10.436/2002 (BRASIL, 2002), o Decreto 5626/2005 (BRASIL, 2005), a Lei 13.146/2015 (BRASIL, 2015), passa a ser entendido não apenas como cumprimento legal, mas como a legitimação e a efetivação das ações dos sujeitos sociais, tendo, assim, seu impacto nos processos de ensino e aprendizagem do aluno surdo. 
Diante do exposto, é a partir dos estudos realizados em torno da Fonologia que se encontram explicações acerca de estruturas prosódicas a partir da identificação de aspectos sintáticos e/ou morfológicos, que caracterizam uma regularidade fonológica como objeto de estudo. A Prosódia das e nas línguas de sinais cada vez mais têm interessado diferentes pesquisadores como Coulter (1979) e Padden (1988) para American Sign Language (ASL); Johnston (1989) para Língua Australiana de Sinais (Auslan); Deuchar (1984) para a Língua Britânica de Sinais (BSL); e Sandler (1999; 2012) para Língua de Sinais Israelense (FENLON; BRENTARI, 2018; SANDLER, 2012).

No Brasil, encontramos estudos recentes acerca da Prosódia da Libras em autores como Santos (2018), Goes (2019), Souza (2020), entre outros, abordando os mais variados aspectos e elementos constitutivos das expressões não manuais. Nesse sentido, entender sobre a importância das articulações faciais como constituintes da linguagem requer compreender que estas fazem parte da prosódia e estão relacionadas com os demais níveis linguísticos.

No intuito de contribuir para o aprofundamento desses estudos nas línguas de sinais, especificamente relacionados à Libras, este artigo apresenta discussões sobre um de seus subcomponentes - a entonação. Para tanto, essa pesquisa tem como objetivo compreender quais são os movimentos faciais de manifestação prosódica de entonação na Libras e suas significações em contexto narrativo. Como metodologia utilizou-se de revisão bibliográfica e análise de uma questão da prova do Exame Nacional do Ensino Médio - ENEM-2017, primeira edição em Libras.

\section{A Fonologia Prosódica}

A Fonologia Prosódica se define por ser uma teoria formal que visa compreender as estruturas prosódicas a partir da identificação de aspectos sintáticos e/ou morfológicos, que caracterizam uma regularidade fonológica como aplicação de estudo. Descreve como se manifestam as porções de enunciados em diferentes línguas, considerando as semelhanças e diferenças, para definir parte da gramática de cada língua, quanto à regularidade da manifestação oral, determinando como o acento frasal se realiza (HORA; MATZENAUER, 2017). Nas línguas de sinais, essas semelhanças e diferenças definem aspectos semânticos conforme o movimento isolado ou combinado de partes físicas faciais como olhos, boca, bochechas, língua, testa, sobrancelhas e nariz.

Como Sandler (2012) afirma, a prosódia possibilita que algumas partes de um enunciado possam ser enfatizados, ressaltando-os em afirmativos, negativos, interrogativos e 
exclamativos. Inclusive avaliando a dependência ou não de um conhecimento necessário compartilhado, como de outros dados pragmáticos. Dessa maneira, a Prosódia investiga não apenas o que se diz, mas como se diz, esmiuçando o tempo, a proeminência ${ }^{3}$, a entonação e a relação entre eles.

\section{Elementos Prosódicos}

Em se tratando de língua oral, ao separar a fala, podem ser explorados os segmentos vogais e consoantes; e as prosódicas - sílabas, moras silábicas ${ }^{4}$, pé ${ }^{5}$, grupo tonal ${ }^{6}$, tons entoacionais $^{7}$, tessitura ${ }^{8}$ e tempo. Porém, há algumas propriedades fonéticas suprassegmentos - que representam a duração segmental, ritmo, altura, nasalização e articulações secundárias, entre outras, também de interesse da fonologia prosódica (FENLON; BRENTARI, 2018; MASSINI-CAGLIARI; CAGLIARI, 2001).

Mas, quando se trata de língua sinalizada, ainda há pouco interesse em se observar como ocorrem os trechos rítmicos, as modulações significativas dos sinais, a ênfase e a entonação. Contudo, Liddell, Baker e Padden, cada qual com sua pesquisa sobre a American Sign Language (ASL), observaram que havia diferenças entre os enunciados e que essas eram manifestadas por configurações da face, cabeça e corpo - constituintes do sintagma entonacional - concomitante com a realização dos sinais. Iniciam-se, a partir da década de 1980, os estudos descritivos de marcadores não-manuais faciais como elementos sintáticos e/ou prosódicos (SANDLER, 2012).

Nesse ínterim, as articulações não-manuais faciais, enquanto marcadoras dos elementos prosódicos, podem ser entendidas como manifestação do ritmo (cronometragem); entonação (rosto); e proeminência (corpo), correlacionados à estrutura rítmica temporal, manifestada pelos sinais manuais. Tais elementos prosódicos citados são percebidos pelos movimentos das sobrancelhas, dos olhos e da cabeça, além das pausas e transições (FENLON; BRENTARI, 2018; SANDLER, 2012).

\footnotetext{
${ }^{3}$ Proeminência - refere-se ao grau em que uma sílaba ou som se destaca dos outros no seu contexto.

${ }^{4}$ Moras silábicas - unidade de duração da fonologia métrica para analisar parte da sílaba denominada rima.

${ }^{5}$ Pé métrico - grupo acentual de extensão variada a depender da taxa da enunciação (elocução). Unidade estrutural rítmica das línguas de ritmo acentual.

${ }^{6}$ Grupo tonal - unidade sonora para classificar uma sequência distintiva de tons numa elocução, podendo corresponder a uma frase, oração ou palavra, caracterizada do ponto de vista entonacional.

${ }^{7}$ Tom - traço do léxico que diz respeito aos padrões de altura da voz de unidades lexicais.

${ }^{8}$ Tessitura - espaço compreendido entre o som mais grave e o mais agudo.

Termos disponíveis no Dicionário de Termos Linguísticos, do ILTEC - Instituto de Linguística Teórica e Computacional. Disponível em: http://www.portaldalinguaportuguesa.org/
} 


\section{Entonação}

A entonação permite uma "rica e sutil mistura de significados [...] como aditivo, seletivo, rotineiro, vocativo, contundente", em um mesmo enunciado, porém produzido com padrões entonacionais diferentes (SANDLER, 2012, p. 61-62). Igualmente, a entonação pode ser analisada nas línguas de sinais por meio da expressão facial, que cumpre as funções pragmáticas da entonação vocal, e pode ser dissociada dos elementos sintáticos do discurso. No que se diferem as línguas orais e de sinais quanto à entonação, é que os marcadores entonacionais orais são sequenciais, enquanto os marcadores entonacionais não-manuais faciais ocorrem simultaneamente.

O exemplo de Sandler (2012, p. 63) - YOU INSULT JANE, GEORGE ANGRY (Você insulta Jane, George zangado) - apresenta dois significados não ambíguos que são percebidos conforme as expressões faciais apresentadas. Se o enunciado for sinalizado com não-manuais faciais neutros, o significado é de uma afirmação "Você insultou Jane e George ficou bravo". Porém, se o mesmo enunciado for sinalizado acompanhado dos marcadores não-manuais faciais como sobrancelhas levantadas e cabeça inclinada durante toda a sinalização, e piscar os olhos na junção das orações, o significado passa a ser de uma condição: "Se você insultar Jane, George ficará zangado". Mesmo que haja um sinal específico para a condicional "Se", nem sempre é necessário seu uso, sendo possível ter o mesmo entendimento da condição pelos marcadores não-manuais faciais apresentados.

Em estudos similares com a Língua de Sinais Israelense, a entonação é percebida na mudança das articulações faciais entre os sintagmas entonacionais, havendo também mudança na posição da cabeça e do corpo. Isso evidencia que nas línguas de sinais, a entonação facial ocorre simultaneamente com todo o constituinte prosódico, diferentemente das línguas orais, quando a ocorrência é sequencial (SANDLER, 2012).

Considerar os movimentos da cabeça, olhos, sobrancelha e testa, e o deslocamento do tronco para frente ou para trás, contribui cada qual com sua significação para o entendimento de um sistema componencial complexo das línguas sinalizadas. Esses constituintes podem ser caracterizados com determinado significado, conforme propôs Coulter (1979). Como exemplo, as sobrancelhas elevadas geralmente significam dependência e/ou continuação (semelhança com o tom alto nas línguas faladas), ou uma condição; olhos semicerrados significam recuperar informações já compartilhadas, ou uma condicional contrafactual; a testa 
franzida, comum em perguntas do tipo “-qu”, significa suposições e/ou uma atitude emocional do sinalizante, conforme o contexto (COUTLER, 1979 apud SANDLER, 2012).

Assim sendo, por se considerar os estudos prosódicos de grande complexidade, elegeu-se como objeto de estudo a entonação manifestada na Libras, e consequentemente, sua influência e contribuição para os possíveis significados produzidos no contexto narrativo analisado.

\section{Pressupostos metodológicos}

Trata-se de um estudo de natureza aplicada, documental, do tipo descritivoexploratório, pelo método observacional. A geração de dados foi realizada em dois momentos distintos: (a) revisão bibliográfica de estudos realizados sobre a prosódia da ASL e Língua de Sinais Israelense, apresentados por Fenlon e Brentari (2018) e Sandler (2012); (b) transcrição e análise da seleção de uma questão da prova do ENEM-2017, em Libras, gravada em vídeo, correspondente à versão escrita em língua portuguesa.

Selecionou-se a primeira questão da área de Ciências Humanas e suas tecnologias, nomeada como "Questão 46", com duração de 1 min 27 seg (Imagem 1), aplicada no primeiro dia de prova, pertencente ao Caderno 10 Verde. Foi considerado para análise apenas o enunciado da questão, por se tratar de um discurso narrativo. $O$ trecho corresponde ao intervalo entre 6 seg 09 centésimos e 51 seg 36 centésimos, totalizando 45 seg 27 centésimos de vídeo para análise. Foram descartados os trechos das alternativas, por apresentarem neutralidade expressiva (sem entonação), necessária à idoneidade do propósito avaliativo do exame, porém não adequada para o estudo proposto.

\section{Imagem 1 - Questão 46 - Vídeo e Texto}

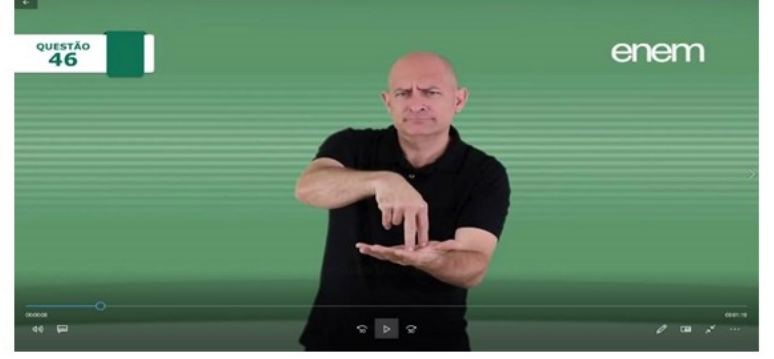

Questōes de 46 a 90

QUESTÃO 46

Parecia coisa de encanto. A gente deixava de ir uns poucos meses num lugar e quando aparecia lá ficava de boca aberta vendo tudo mudado: casas novas, negocios sortidos como os de Corte, igreja, circo de cavalinhos, botica, e o mato, o que é dele? Trem de ferro ia comendo udo, tal e qual como na terra brava depois do roçado quando a plantaçăo brota.

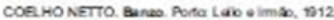

O relato do texto ressalta o uso da técnica como um instrumento para

Q simplificar o trabalho humano.

(3) registrar os hábitos cotidianos.

C) aumentar a produtividade fabril.

(D) fortalecer as culturas tradicionais.

(9) transformar os elementos paisagisticos. 
Fonte: INEP - ENEM (2017); PDF da prova ENEM (2017) ${ }^{9}$

Os dados foram transcritos por meio do software ELAN 5.3 (EUDICO Linguistic Annotator), desenvolvido pelo Max Planck Institute for Psycholinguistics. Tratando-se da língua de sinais, permite o registro de comentários, descrição da situação de interação, de sons associados à produção de sinais, marcações não manuais, linhas para anotações das glosas, tradução para outra língua, dentre outros (CHRISTMANN et al., 2010).

Para esse estudo, as trilhas (linhas) foram nomeadas com a combinação de letras e termos. Foram elencados cinco critérios a serem transcritos e analisados: (1) movimento dos olhos (MOV-O); (2) movimento das sobrancelhas (MOV-S); (3) movimento da testa (MOV$\mathrm{T})$; (4) movimento da cabeça (MOV-C); e o (5) significado prosódico (SP), dividido em quatro trilhas, referentes a cada elemento facial, nomeadas SP-O, SP-C, SP-S e SP-T.

Ao todo foram realizadas 224 anotações sobre os quatro elementos não-manuais faciais constituintes da prosódia, tanto sobre seus movimentos quanto aos possíveis significados. Para a análise do fragmento do vídeo foram determinados 326 seg 16 centésimos em anotações, com uma duração média de 1 seg 45 centésimos, entre intervalos de 18 centésimos de segundo a 18 seg 72 centésimos.

\section{Resultados e análise dos dados}

Quanto à revisão bibliográfica, foram analisados os movimentos faciais superiores apresentados como constituintes prosódicos nas línguas de sinais israelense e americana, pesquisados por Sandler (2012) e Fenlon e Brentari (2018), respectivamente. Foram analisados quatro elementos faciais e os tipos de movimentos realizados por eles, bem como a determinação de seus significados prosódicos.

Em relação à cabeça, observaram-se quatro movimentos distintos: neutro, longitudinal (rotação), latitudinal (flexão/extensão) e lateralização (inclinação). Quanto aos olhos, foram determinados seis movimentos: neutro, longitudinal (lateralização), latitudinal (para cima e para baixo), fechados ou semicerrados, arregalados, piscando (um ou dois olhos). Sobre as sobrancelhas, elencaram-se cinco movimentos: neutras, erguidas (para cima), franzidas (para baixo), alternadas, e arqueadas. E quanto à testa, determinaram-se dois movimentos: arqueada e franzida. Essa revisão possibilitou a criação do Quadro 1, apresentada nos resultados.

9 Disponível em: http://enemvideolibras.inep.gov.br/2017/videoprova.html?prova=p2 Acesso em: 21 de novembro de 2018. 
Para a verificação se os elementos faciais da ASL e da Língua de Sinais Israelense são manifestados de igual forma na Libras e constituem os mesmos significados, foi realizada a transcrição do vídeo, em trilhas dos movimentos de cada constituinte não-manual: cabeça, olhos, sobrancelhas e testa, considerando o Quadro 1 como indicativo dos movimentos possíveis. Em seguida, foram verificados se os possíveis significados apresentados na mesma tabela eram condizentes com o contexto da questão em análise. O vídeo da questão 46 faz referência a um trecho da obra "Banzo" (1912, p. 16), de Coelho Neto, romancista realista brasileiro.

Seguindo a ordenação das trilhas, obteve-se na trilha MOV-C 37 anotações, correspondendo em SP-C à mesma quantidade de anotações. A duração média dos movimentos da cabeça foi de 1 seg 21 centésimos. Quanto à trilha MOV-O, foram percebidos 46 casos, também correspondentes às anotações da trilha SP-O, sendo sua duração média de 97 centésimos. Nas trilhas MOV-S e SP-S foram obtidas igualmente 20 anotações. A duração média desses movimentos corresponde a 2 seg 25 centésimos, porém tendo uma duração máxima de 10 seg 01 centésimo. E, por fim, sobre a análise da testa, na trilha MOV-T foram verificados 12 casos, com duração média de 3 seg 7 centésimos, mas com uma duração máxima de 18 seg 72 centésimos. Porém, na trilha dos significados prosódicos correspondente SP-T, foram registrados apenas 6 casos. Isso devido ao fato de não se ter significado quando a testa se encontra na posição neutra (sem movimentação).

Cabeça: Quanto aos movimentos da cabeça e possíveis significados prosódicos, puderam ser verificadas 37 ocorrências, divididas em: (a) NEUTRA: 16 ocorrências compreendidas como "afirmativas", ainda que uma delas tenha característica de "acabamento"; (b) FLEXÃO (para baixo): foram percebidas nove manifestações, das quais sete foram verificadas como "ênfase", e duas como "função locativa"; (c) ROTAÇÃO DIREITA: foram quatro casos, sendo dois como "foco" e os outros como "função locativa"; (d) INCLINAÇÃO DIREITA: obteve-se igualmente quatro casos que significaram a "confirmação" de foco ou de função locativa, apresentados pela rotação à direita; (e) EXTENSÃO (para cima): três situações se apresentaram, sendo apenas uma como "interrogativa" e as outras duas como "aditiva"; (f) INCLINAÇÃO ESQUERDA: apenas um caso foi observado, o que corresponde a uma suposição. 
Olhos: Na transcrição e análise realizada dos movimentos dos olhos, nos 46 casos das trilhas MOV-O e SP-O, foram observados os seguintes dados: (a) NEUTRO: foram encontrados 21 casos em que a direção do olhar se encontra no centro, tendo como entendimento "afirmação"; (b) LATITUDINAL PARA BAIXO: obtiveram-se 14 casos, significando ora "ênfase" (seis), ora "foco" (oito). Diferenciaram-se tais significados pelo tempo médio de duração, sendo a ênfase um tempo maior e o foco uma duração menor; (c) LONGITUDINAL PARA DIREITA: encontrou-se apenas um caso, significando a ocorrência de uma "oração relativa"; (d) FECHAR: foram verificados cinco eventos, um no início do trecho analisado, significando "aceitação", e os outros quatro indicaram "transição" entre enunciados; (e) SEMICERRAR: as três ocasiões percebidas indicaram a retomada de "informação compartilhada"; (f) ARREGALAR: apenas uma ocorrência desse movimento, evidenciando "intensidade"; (g) PISCAR (consecutivamente): observou-se uma ocorrência, apresentando um entendimento de "contradição".

Sobrancelhas: Sobre os movimentos das sobrancelhas, transcritos na trilha MOV-S, foram encontrados 20 eventos, tendo a mesma quantidade correspondente na trilha SP-S, sobre os significados. Assim sendo, verificaram-se quatro aspectos diferentes: (a) NEUTRA: quando não há movimento algum, foram encontrados oito casos, todos indicando "afirmação"; (b) ERGUIDA: das cinco verificações, duas indicaram "admiração", outras duas, "continuação", e uma "condição"; (c) FRANZIDA: ao todo foram seis casos visualizados, sendo cinco compreendidos como "ênfase" e um outro como pergunta do tipo “qu", possíveis de serem diferenciados a partir de outros elementos não-manuais constituintes concomitantes; (d) ARQUEADA: quando apenas uma das sobrancelhas apresenta movimento, obteve-se um evento, entendido como "alternância".

Testa: Para a transcrição e análise dos movimentos da testa, foram determinados 12 casos, divididos em apenas duas circunstâncias: (a) NEUTRA: aparecendo em seis momentos; e (b) ARQUEADA: quando encontra-se erguida, sendo mais seis casos. Em relação aos significados, apenas foram indicados os referentes aos arqueamentos, entendendo que a testa, na posição neutra, não determina nenhum entendimento. Assim sendo, foram verificadas duas ocorrências compreendidas como "admiração", duas outras como "continuação", uma como "dependência" e outra em pergunta do tipo “-qu". Não foi elaborado gráfico referente aos 
dados analisados a respeito da testa, por ser encontrado um único movimento no trecho em questão.

A partir da revisão bibliográfica elaborou-se o Quadro 1, com os resultados das pesquisas que apresentaram a caracterização dos movimentos faciais superiores como constituintes prosódicos e as possíveis significações assumidas nas línguas de sinais americana e israelense.

Quadro 1 - Caracterização de Movimentos Faciais Superiores

\begin{tabular}{|c|c|c|c|c|}
\hline ELEMENTO & MOVIMENTO & \multicolumn{2}{|c|}{ SIGNIFICAÇÃO } & IMAGEM \\
\hline \multirow{4}{*}{ CABEÇA ${ }^{10}$} & $\begin{array}{c}\text { NEUTRO } \\
\text { Sem movimento } \\
\text { Eixo normal }\end{array}$ & \multicolumn{2}{|c|}{$\begin{array}{l}\text { Afirmação } \\
\text { Acabamento }\end{array}$} & \\
\hline & $\begin{array}{l}\text { LONGITUDINAL } \\
\text { Rotação } \\
\text { Para a direita } \\
\text { Para a esquerda }\end{array}$ & \multicolumn{2}{|c|}{$\begin{array}{c}\text { Foco } \\
\text { Função Locativa } \\
\text { Transição } \\
\text { Contradição }\end{array}$} & \\
\hline & $\begin{array}{c}\text { LATITUDINAL } \\
\text { Flexão/extensão } \\
\text { Para baixo } \\
\text { Para cima }\end{array}$ & $\begin{array}{l}\text { Para baixo } \\
\text { Ênfase } \\
\text { Pausa } \\
\text { Função } \\
\text { Locativa } \\
\end{array}$ & $\begin{array}{c}\text { Para cima } \\
\text { Interrogativa } \\
\text { Negativa } \\
\text { Aditiva }\end{array}$ & \\
\hline & $\begin{array}{l}\text { LATERALIZAÇÃO } \\
\text { Inclinação } \\
\text { Para a direita } \\
\text { Para a esquerda }\end{array}$ & $\begin{array}{c}\text { À direita } \\
\text { Confirmação }\end{array}$ & $\begin{array}{c}\text { À esquerda } \\
\text { Suposição } \\
\text { Dúvida }\end{array}$ & \\
\hline ELEMENTO & MOVIMENTO & \multicolumn{2}{|c|}{ SIGNIFICAÇÃO } & IMAGEM \\
\hline OLHOS & $\begin{array}{c}\text { NEUTRO } \\
\text { Foco normal }\end{array}$ & \multicolumn{2}{|c|}{ Afirmação } & \\
\hline
\end{tabular}

\footnotetext{
${ }^{10}$ As imagens representativas da cabeça foram criadas no software Paint 3D, da Microsoft Corporation (2016).

${ }^{11}$ Disponível em: https://zadbajosiebie.pl/jak-wykonac-prosty-makijaz-oka/. Acesso em: 10 set. 2020.
} 


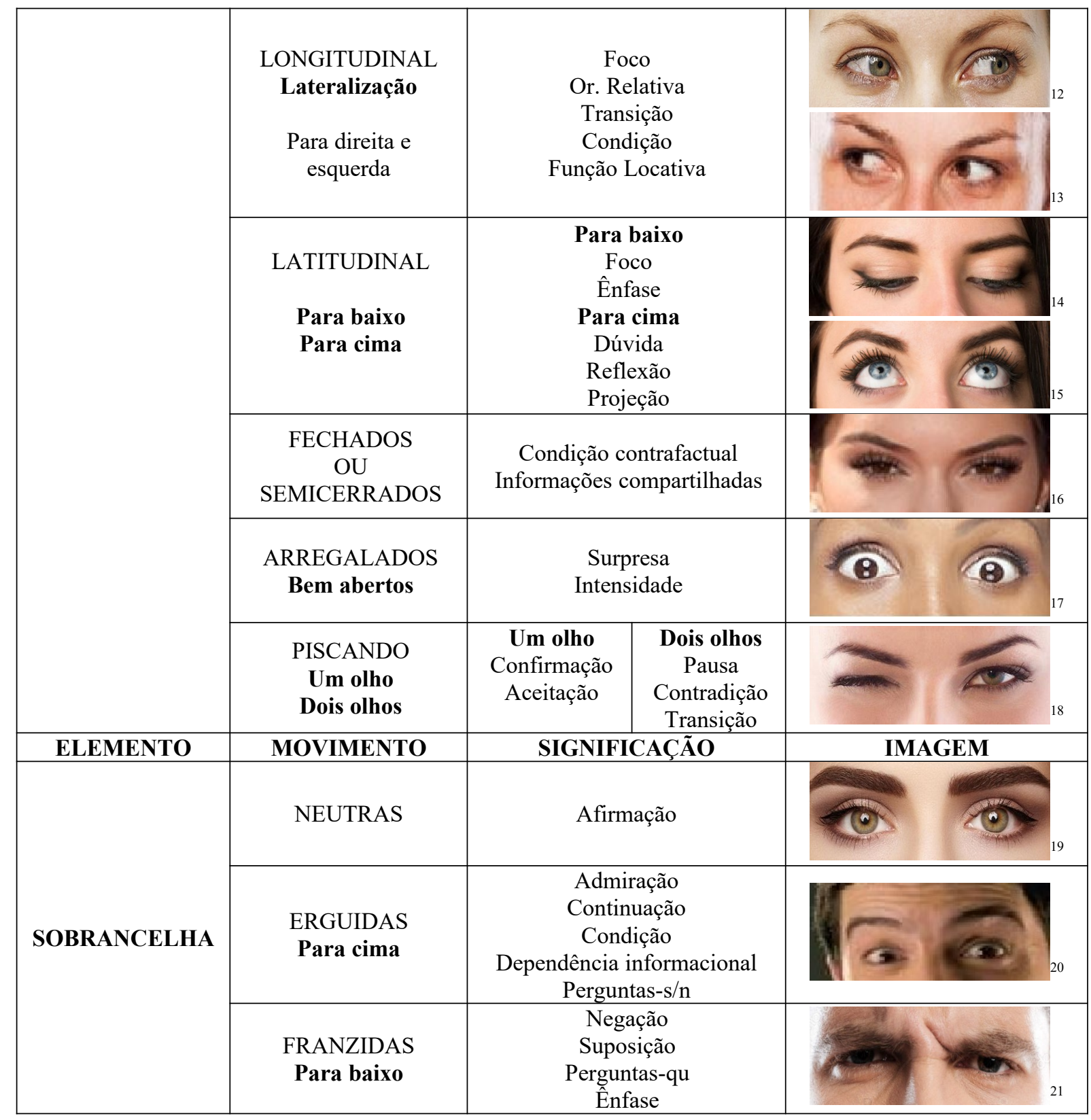

\footnotetext{
${ }^{12}$ Disponível em: https://www.gettyimages.pt/detail/foto/woman-looking-to-side-close-up-imagem-royalty-free/ 200478827-001. Acesso em: 10 set. 2020.

${ }^{13}$ Disponível em: https://pt.freeimages.com/premium/suspicious-young-woman-looking-to-the-side-1626989. Acesso em: 10 set. 2020.

${ }^{14}$ Disponível em: https://br.freepik.com/fotos-premium/macro-close-up-de-olhos-de-mulher-olhando-parabaixo 2350450.htm. Acesso em: 10 set. 2020.

${ }^{15}$ Disponível em: https://br.freepik.com/fotos-premium/macro-close-up-de-olhos-de-mulher-olhando-paracima 2350449.htm. Acesso em: 10 set. 2020.

${ }^{16}$ Disponível em: https://revistaglamour.globo.com/Lifestyle/noticia/2015/08/tatica-do-momento-pra-selfieperfeita-gente-ensina.html. Acesso em: 10 set. 2020.

${ }^{17}$ Disponível em: https://www.gettyimages.com/detail/photo/terrified-young-woman-customer-royalty-freeimage/173233567. Acesso em: 10 set. 2020.

${ }^{18}$ Disponível em: https://www.recantodasletras.com.br/cronicas/4438183. Acesso em: 10 set. 2020.

${ }^{19}$ Disponível em: https://zadbajosiebie.pl/jak-wykonac-prosty-makijaz-oka/. Acesso em: 10 set. 2020.

${ }^{20}$ Disponível em: https://www.pinterest.ch/pin/761952830675913861/. Acesso em: 10 set. 2020.

${ }^{21}$ Disponível em: https://ru.depositphotos.com/156528832/stock-photo-man-holding-tweezer-andfrowning.html. Acesso em: 10 set. 2020.
} 


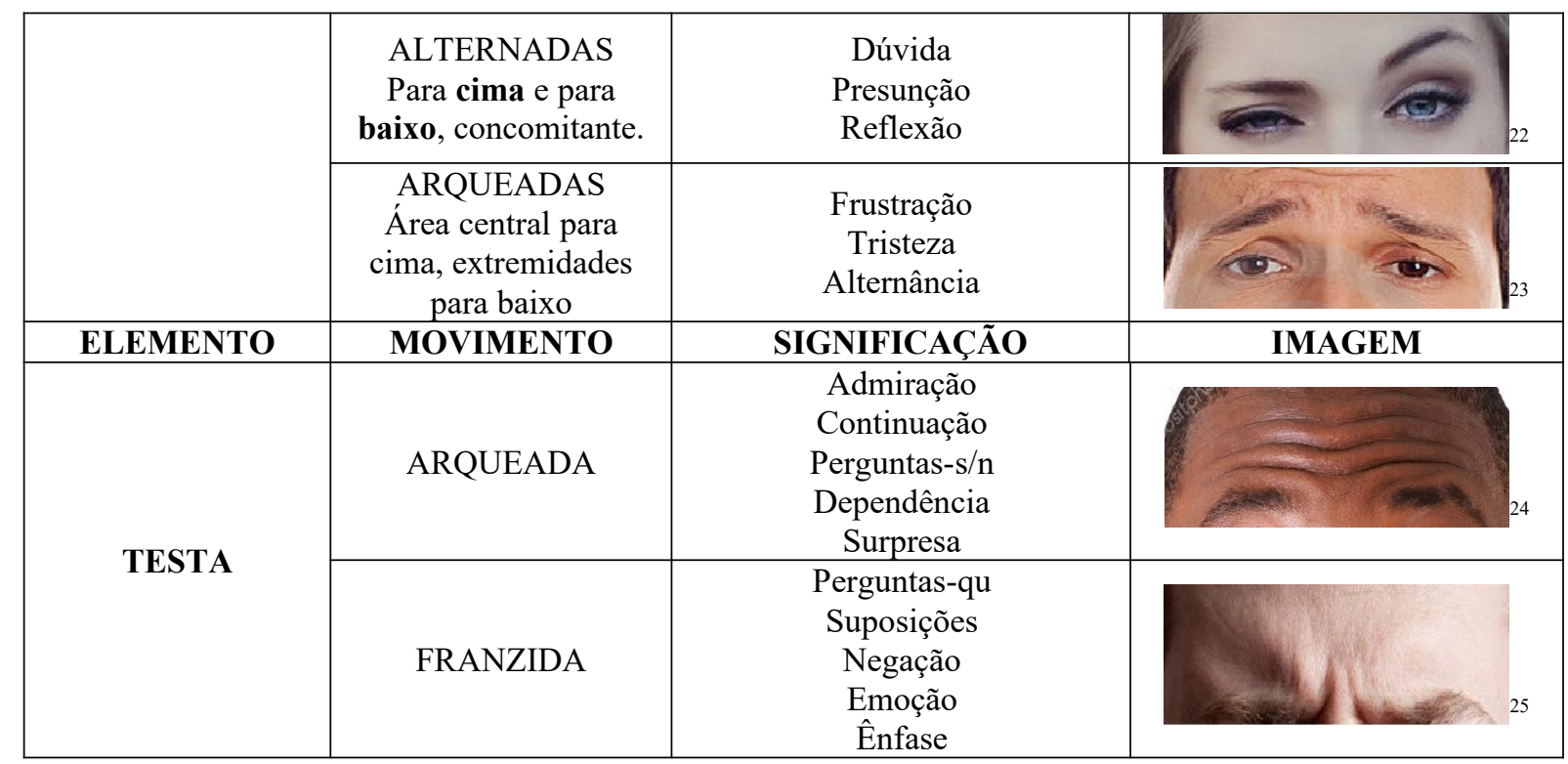

Fonte: Dados da pesquisa

A partir da análise do vídeo, foi elaborada uma segunda tabela, considerando as manifestações prosódicas na Libras, comprovando a existência dessas manifestações com iguais significados, em contexto narrativo.

Quadro 2 - Movimentos Faciais Da Libras Em Contexto Narrativo

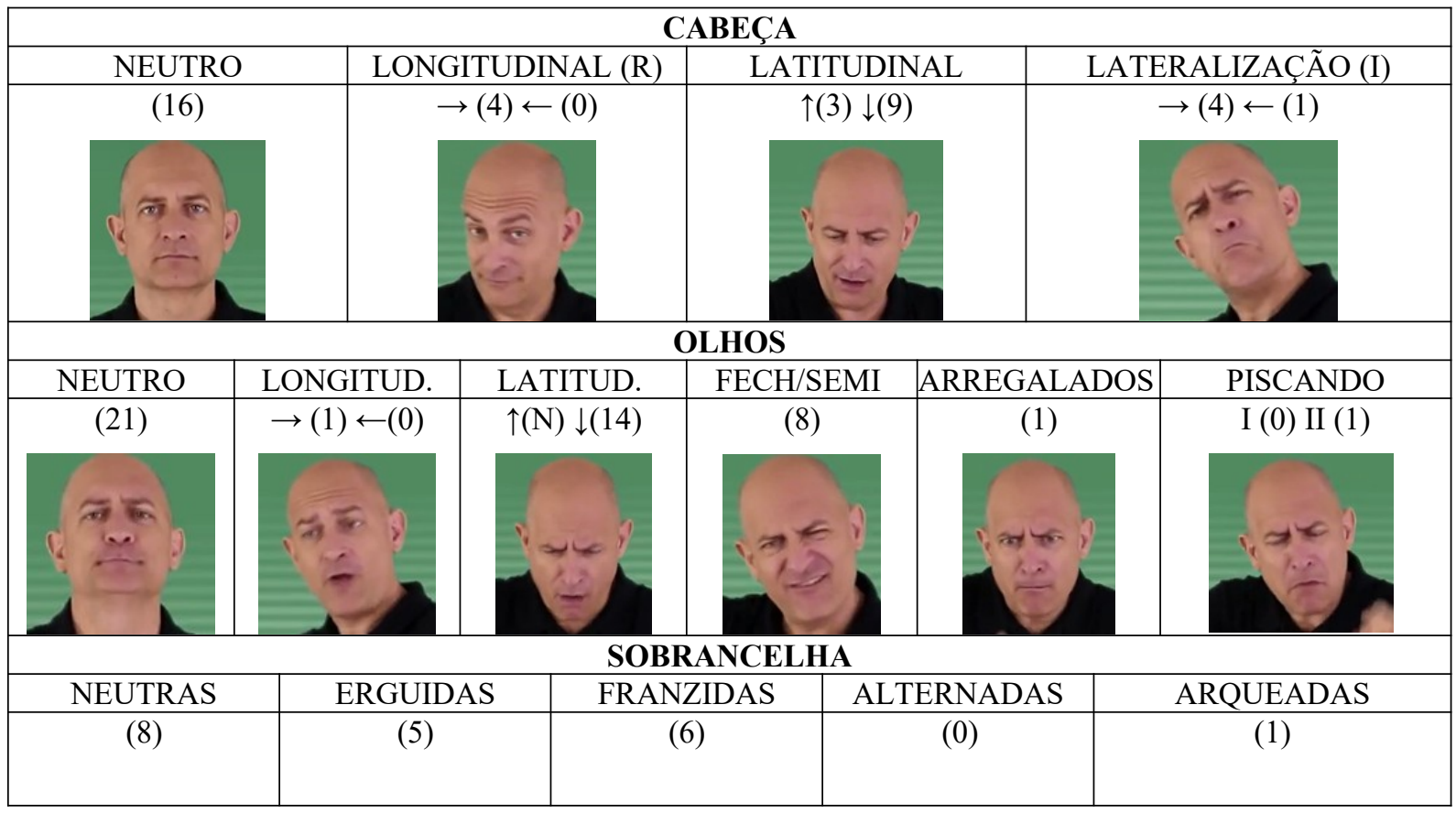

${ }^{22}$ Disponível em: https://pt.srathbun.com/beauty/6098-srosshiesya-brovi-u-muzhchin-zhenschin-i-podrostkovchto-oni-oznachayut-i-kak-ih-ubrat-navsegda-kak-udalit-srosshiesya-brovi-doma.html. Acesso em: 10 set. 2020. ${ }^{23}$ Disponível em: https://www.thecoli.com/threads/faces-of-africa.212015/page-29. Acesso em: 10 set. 2020.

${ }^{24}$ Disponível em: https://pt.depositphotos.com/44539155/stock-photo-males-face-showing-surprise.html. Acesso em: 10 set. 2020.

${ }^{25}$ Disponível em: https://www.prestigeoralsurgery.com/2014/08/15/what-complications-are-possible-after-theremoval-of-wisdom-teeth/. Acesso em: 10 set. 2020. 


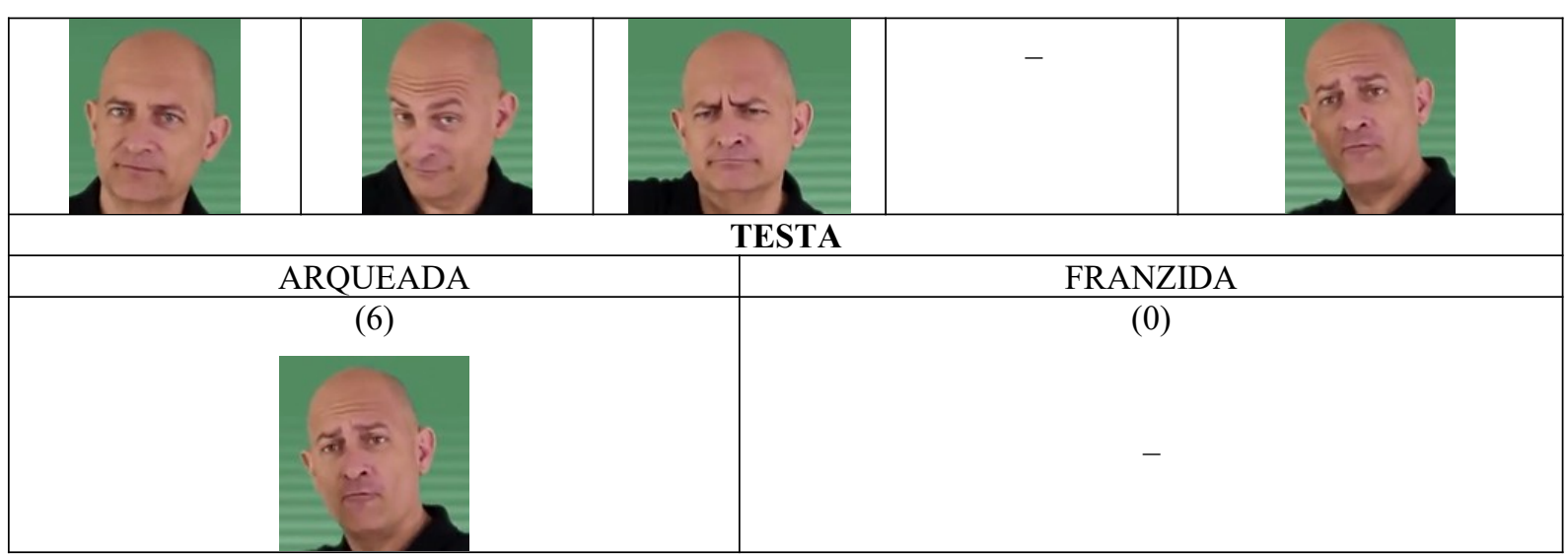

Fonte: Dados da pesquisa

A partir dos dados gerados e dos resultados obtidos, pode-se considerar a igualdade de ocorrência das manifestações prosódicas na Libras, em relação às apresentadas na ASL e na Língua de Sinais Israelense. Apesar de cada constituinte ter sido transcrito e analisado individualmente, sabe-se que é no conjunto das manifestações destes que se tem uma compreensão do significado contextual, enquanto manifesto prosódico. Diante disso, foram observados quais movimentos não-manuais são mais evidentes, quando analisados a partir desse conjunto de constituintes, correlacionados à sinalização. Portanto, esses conjuntos, a partir do início de um enunciado (início da sinalização) até uma pausa ou transição, manifestados por diferentes ocorrências (piscar dos olhos, movimento em direção oposta da cabeça, ou movimento para posição central neutra da cabeça), resultaram em 12 intervalos nomeados pela letra 'F', seguido de numeração correspondente do 1 ao 12 .

O F-1 (6"08-8"12) ${ }^{26}$ correspondente ao início do trecho da análise, apresenta uma manifestação afirmativa, iniciada por uma admiração focada, perpassada enfaticamente de maneira sutil (rápida). Pode-se compreender como uma estratégia inicial para atrair a atenção do(s) interlocutor(es), por se tratar de discurso narrativo. O F-2 (8"12-14"08) deixa evidente duas transições, uma relacionada a um tempo passado e outra a um tempo mais atual. $\mathrm{O}$ intervalo entre essas transições promove no(s) interlocutor(es) a sensação de fazer parte do contexto, por afirmar que isso é de conhecimento de todos.

Quanto ao F-3 (14”08-17”72), há uma evidência de contradição, que é afirmada intensa e enfaticamente. Em seguida, no intervalo do F-4 (17"72-18"58) é feita uma referência a um questionamento, para esclarecer o contexto do F-3. A resposta é entendida em F-5 (18"58-25"55) quando responde o questionamento anterior, em uma afirmativa enfática.

\footnotetext{
${ }^{26}$ Aspas dupla - representa o termo 'segundos', por exemplo em 6"08 lê-se seis segundos e oito centésimos.
} Assim deve ser entendido nos demais trechos indicativos de tempo. 
Em se tratando do F-6 (25"55-30"91), é iniciado um novo enunciado aditivo com informações compartilhadas. Essas informações ora aparecem como foco, ora são enfatizadas e confirmadas. A diferenciação entre o foco e a ênfase foi percebida pela duração de cada ocorrência, tendo a ênfase um tempo maior de realização. O F-7 (30"91-35"13) enfatiza a continuidade do enunciado afirmativo, com admiração. Essa admiração é considerada como uma informação compartilhada, envolvendo novamente o(s) interlocutor(es) no contexto.

O F-8 (35"13-35"63) é bem caracterizado por uma transição de dependência, com uma condicional. Em F-9 (35"63-37"89), há a presença de uma função locativa como introdutória a uma interrogativa, tendo o foco no objeto constituinte da locação. E em F-10 (37"89-43"45), responde-se ao questionamento anterior por meio de uma suposição composta de função locativa enfatizada, como afirmação à suposição. O F-11 (43"45-49"13) apenas dá continuidade ao contexto anterior, adicionando enfaticamente a afirmativa apresentada de outra função locativa. Por fim, em F-12 (49"13-51"37) há apenas a confirmação do que foi apresentado, tendo, em seguida, o retorno na posição neutra.

Diante disso, é possível afirmar que a prosódia entonacional da Libras comprova que esses elementos faciais e seus movimentos são relevantes para a produção, significação e compreensão da linguagem nos momentos de interação para a construção do sentido da mensagem. São constituintes não-manuais faciais diferenciados, observados pelo interlocutor que recebe, bem como pelo interlocutor que está manifestando um discurso, construindo o sentido da língua pelas expressões dos movimentos faciais superiores. A atenção a esses aspectos contribui, assim, tanto para a proficiência da Libras quanto para a construção de significados entre os falantes/sinalizantes.

\section{Considerações finais}

Nesse estudo evidenciou-se que pesquisas sobre os elementos constituintes das línguas de sinais americana e israelense ocorreram de igual maneira na Libras. Ressaltamos aqui o papel fundamental de divulgação e esclarecimento sobre a estrutura e funcionamento linguístico da Libras, no que tange à prosódia das línguas de sinais. Não se relaciona somente à afetividade, à expressão de emoções, mas a Prosódia perpassa todos os níveis linguísticos e encadeia a interação, dando forma, significação e função ao diálogo. 
Estudos sobre os aspectos da Fonologia Prosódica subsidiam pesquisas de outras áreas, como a Literatura surda e seu universo de investigação em narrativas de diferentes gêneros discursivos, bem como as pesquisas que envolvem a interpretação e tradução bimodal entre línguas de sinais e línguas orais. Também instigam novos olhares a respeito do ensino e aprendizagem das línguas de sinais, assumindo lugar de significação das línguas sinalizadas.

Em se tratando da Educação, a pesquisa tem também implicações para a área, uma vez que este conhecimento contribui aos atores presentes nas escolas e universidades, concorrendo para uma atuação responsiva quanto aos planejamentos e currículos educacionais bilíngues, respeitando as realidades psicossocial, cultural e linguística das comunidades surdas.

\section{REFERÊNCIAS}

BRASIL. Lei n. 10.436/2002. Dispõe sobre a Língua Brasileira de Sinais e dá outras providências. Brasília, DF: Presidência da República, 2002. Disponível em: http://www.planalto.gov.br/ccivil_03/leis/2002/110436.htm. Acesso em: 14 maio 2021.

BRASIL. Decreto n. 5.626/2005. Regulamenta a Lei $n^{\circ} 10.436$, de 24 de abril de 2002, que dispõe sobre a Língua Brasileira de Sinais - Libras, e o art. 18 da Lei no 10.098 , de 19 de dezembro de 2000. Brasília, DF: Presidência da República, 2005. Disponível em: http://www.planalto.gov.br/ccivil_03/_ato2004-2006/2005/decreto/d5626.htm. Acesso em: 14 maio 2021.

BRASIL. Lei n. 13.146/2015. Institui a Lei Brasileira de Inclusão da Pessoa com Deficiência (Estatuto da Pessoa com Deficiência). Brasília, DF: Presidência da República, 2015. Disponível em: http://www.planalto.gov.br/ccivil_03/ ato2015-2018/2015/lei/113146.htm. Acesso em: 14 maio 2021.

CHRISTMANN, K. E. et al. O software ELAN como ferramenta para transcrição, organização de dados e pesquisa em aquisição da língua de sinais. In: ENCONTRO DO CELSUL, 9., 2010, Palhoça. Anais [...]. Palhoça, SC: UNISUL. 2010.

DUARTE, R. L.; MESQUITA, R. Considerações acerca do code-bleding ou sobreposição de línguas e suas relações com o code-switching. Revista Sinalizar, v. 1, n. 1, p. 37-47, jan./jun. 2016.

FENLON, J.; BRENTARI, D. (toappear). Sign language prosody. In: QUER, J.; PFAU, R.; HERRMANN, A. (Eds.), Routledge Handbook of Theoretical and Experimental Sign Language Research. 2018.

GOES, A. K. S. Marcadores prosódicos da Libras: o papel das expressões corporais. 2019. 65 f. Dissertação (mestrado em Linguística) - Faculdade de Letras, Universidade Federal de 
Alagoas, Maceió, 2019. Disponível em:

http://www.repositorio.ufal.br/bitstream/riufal/5869/1/Marcadores\%20pros\%c3\%b3dicos $\% 20 \mathrm{da} \% 20$ libras $\% 20 \mathrm{o} \% 20$ papel\%20das $\% 20$ express $\%$ c3\%b5es\%20corporias.pdf. Acesso em: 14 maio 2021.

HORA, D.; MATZENAUER, C. L. (org.) Fonologia, fonologias: uma introdução. São Paulo: Contexto, 2017. 192 p.

MASSINI-CAGLIARI, G.; CAGLIARI, L. C. Fonética. In: MUSSALIM, F; BENTES, A C. (org.). Introdução à Linguística: domínios e fronteiras. São Paulo: Cortez, 2001. v. 1-2, p. 105-146.

SANDLER, W. Visual prosody. In: PFAU, R.; STEINBACH, M.; WOLL, B. (Eds.). Sign Language. Na International Handbook. Berlin: Mouton de Gruyter, 2012. p. 55-76.

SANTOS, R. F. A autoria na interpretação de Libras para o Português: aspectos prosódicos e construção de sentidos na perspectiva verbo-visual. 2018. 212 f. Dissertação (Mestrado em Linguística Aplicada e Estudos da Linguagem) - Pontifícia Universidade Católica de São Paulo, São Paulo, 2018. Disponível em: https://repositorio.ufsc.br/bitstream/handle/123456789/192733/SANTOS\%20Ricardo $\% 20$ Ferreira $\% 202018 \% 20 \% 28$ disserta\%c3\%a7\%c3\%a3o\%29\%20PUC\%20SP.pdf? sequence $=1 \&$ isAllowed $=y$. Acesso em: 14 maio 2021 .

SOUZA, D. T. A constituência prosódica da Língua Brasileira de Sinais (Libras): as expressões não manuais. 2020. 179 f. Tese (Doutorado em Letras) - Instituto de Letras, Universidade Federal do Rio Grande do Sul, Porto Alegre, 2020. Disponível em: https://lume.ufrgs.br/bitstream/handle/10183/217373/001121124.pdf? sequence $=1 \&$ isAllowed=y. Acesso em: 14 maio 2021 .

\section{Como referenciar este artigo}

SILVA, R. C.; SANTANA, A. P. O. Prosódia na Libras - um estudo do Corpus do Enem2017. Revista Ibero-Americana de Estudos em Educação, Araraquara, v. 16, n. 3, p. 1963 1978, jul./set. 2021. e-ISSN: 1982-5587. DOI: https://doi.org/10.21723/riaee.v16i3.15133

Submetido em: $16 / 12 / 2020$

Revisões requeridas em: 10/01/2021

Aprovado em: 12/02/2021

Publicado em: 01/07/2021 